\section{(6) OPEN ACCESS}

\title{
Two cross-sectional studies in south India assessing the effect of an HIV prevention programme for female sex workers on reducing syphilis among their clients
}

Subramanian Potty Rajaram, ${ }^{1,2}$ Pradeep Banandur, ${ }^{1,3}$ Usha K Thammattoor, ${ }^{1,4}$
Tinku Thomas, ${ }^{1,4}$ Mandar K Mainkar, ${ }^{5}$ Ramesh Paranjape, ${ }^{5}$ Rajatashurva Adhikary, ${ }_{1}^{6}$
Thierry Duchesne, ${ }_{1}^{7,8}$ Banadakoppa M Ramesh, ${ }^{1,3}$ Shajy Isac, ${ }^{2}$ Stephen Moses, ${ }^{1,2,9}$
Michel Alary ${ }^{7,8,10}$

- Additional material is published online only. To view please visit the journal online (http://dx.doi.org/10.1136/ sextrans-2013-051301).

For numbered affiliations see end of article.

\section{Correspondence to} Dr Subramanian Potty Rajaram Karnataka Health Promotion Trust (KHPT), IT Park, Rajajinagar Industrial Area, Behind KSSIDC Admin Office, Rajajinagar, Bangalore 560044, Karnataka, India; rajaram@khpt.org

Received 25 July 2013 Revised 20 March 2014 Accepted 4 April 2014 Published Online First 8 May 2014

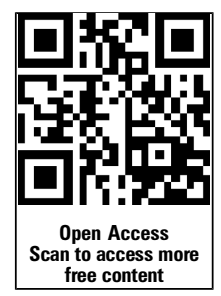

\section{ABSTRACT}

Objective To assess the impact of the Avahan HIV prevention programme for female sex workers (FSWs) in south India on reducing syphilis prevalence among their clients, by comparing rates of syphilis over time as reported in two large-scale surveys of FSWs' clients. Methods A random-effect multilevel logistic regression analysis was performed using syphilis as the dependent variable, with individual independent variables (from the two survey rounds) at level 1 and the district-level programme (from the Avahan computerised monitoring and information system) and contextual variables (from Indian government datasets) at level 2. Programme variables included their 2006 value and their difference in value between 2008 and 2006, as well as the interaction between the latter and the study round. The analysis also controlled for baseline syphilis prevalence and its interaction with the study round.

Results Syphilis decreased significantly among FSWs' clients, from $4.8 \%$ (round 1) to $2.6 \%$ (round 2), $p<0.001$. The OR of the interaction term between the difference in programme coverage of FSWs and the round was $0.98(p=0.023)$, suggesting that increased coverage was associated with a reduced incidence of syphilis.

Conclusions This study suggests that the Avahan intervention programme among FSWs reduced syphilis rates among their clients.

\section{INTRODUCTION}

In India, preventing the transmission of HIV and other sexually transmitted infections (STIs) is an important public health priority. ${ }^{1}$ The primary drivers of the HIV epidemic in India are unprotected sex in the context of the sex trade, unprotected anal sex between men and injection drug use. ${ }^{2}$ Female sex workers' (FSWs') clients constitute an important bridging population for transmitting HIV/STI to the general population. ${ }^{3-5}$ As syphilis is a curable STI responding more quickly to preventive interventions than HIV infection, and given the association between syphilis and $\mathrm{HIV}^{6-8}$ studying the impact of HIV/STI prevention programmes on syphilis prevalence is of particular interest. Despite decades of efforts, there are problems in effective implementation of STI control programmes, because STIs are not simply medical problems but also have complex behavioural, social, political and economic aspects. ${ }^{9}$ Changing STI epidemiology worldwide might prove challenging for control efforts owing to such factors as the failure to avoid unsafe sex, people with infection not accessing health services, the failure to identify and treat patients with symptoms and the failure of health services' to provide adequate treatment. ${ }^{9}$

Avahan, the India AIDS Initiative of the Bill \& Melinda Gates Foundation, a comprehensive HIV prevention programme, has been operational in the six most affected Indian states since 2004. ${ }^{10}$ Although the Avahan programme was implemented in six Indian states, this analysis uses data from four southern states, where heterosexual HIV transmission is predominant. Details of the programme are presented in the online supplementary material. The programme is essentially aimed at high-risk groups, especially FSWs, and only covers their clients indirectly by targeting truck drivers (who are known to be frequent users of sexual services) and men in hot spots with a high concentration of FSWs. The programme effect was expected through a combination of strategies focusing on a 'core' group. This included communication aimed at behavioural change to reduce the number of sexual partners, condom distribution and promotion, and STI treatment. Since 2008 , the programme has been progressively transferred to the management of community-based organisations and government agencies.

Since a randomised design was not feasible, the Avahan evaluation plan adopted sophisticated mathematical models to estimate the programme's impact on high-risk populations and the general population, based on serial cross-sectional integrated behavioural and biological assessment surveys (IBBAs) among high-risk groups, as well as general population surveys. ${ }^{11-14}$ In addition, numerous studies based on statistical models using HIV surveillance data on pregnant women have been carried out to understand the impact of Avahan. ${ }^{15-17}$

Previous analyses using IBBA data on FSW' clients did not consider all 17 districts; they 
examined HIV/STI risk factors in districts of selected states based on the first round of the survey. ${ }^{18} 19$ The effect of the programme on the prevalence of HIV/STI among FSWs' clients has not been examined using both rounds of IBBA data. In this paper, we attempted to understand the effect of Avahan on syphilis prevalence among FSWs' clients using statistical techniques.

\section{METHODS}

\section{Data sources}

This study is based on data from two rounds of IBBA among FSWs' clients in 17 target districts of four southern Indian states (Karnataka, Tamil Nadu, Andhra Pradesh and Maharashtra). The study design, including all the procedures followed for the IBBA surveys, has been described elsewhere ${ }^{1820}$ and is summarised in the online supplementary material methods section.

A standard set of core programme indicators was available for all districts covered by Avahan as part of a management information system and the details of these indicators are discussed elsewhere. ${ }^{21}$ We estimated (1) programme coverage (the proportion of FSWs ever contacted by the programme in a given year); (2) the proportion of FSWs contacted monthly and (3) the proportion of condom requirements met in a given year. Details of the estimation of these three indicators are provided in the online supplementary material methods section. These three indicators were computed for the years 2006-2008 as the information was only complete for all districts for this time period. (The programme's transfer to the government only began in 2008.) We used the value of the indicators in 2006 and the difference in the value between 2008 and 2006 in the statistical analysis.

We also employed several contextual variables at the district level collected from multiple sources for all 17 districts. The complete list of variables used in our analyses is provided in online supplementary appendix table 1 . The contextual variables reflect the districts' sociodemographic and economic development and these influence the sex work environment.

The ethics committees of all institutions involved in the data collection approved the study and its consent procedures. (Details of ethical considerations are given in the online supplementary material methods section.)

\section{Statistical analyses}

We examined the prevalence of syphilis, HIV, Chlamydia trachomatis (CT) and Neisseria gonorrhoeae (NG) among FSWs' clients in both study rounds for all 17 IBBA districts. Demographic and behavioural differences in FSWs' clients between study rounds were studied. We also examined the differences in syphilis prevalence between study rounds according to individual characteristics. Variables were selected based on the existing literature and earlier research using IBBA client data. ${ }^{18} 19$ Subsequently, we constructed multilevel logistic regression models, with syphilis as the dependent variable. Since our main interest was the difference in syphilis prevalence between the rounds, the study round was the main independent variable in the analysis. First, we considered the individual variables in the multilevel logistic regression model, with a random intercept for the districts and a random coefficient for the round, as the difference in HIV prevalence varied widely amongst districts. We retained all individual variables with $\mathrm{p}$ values $\leq 0.05$ in the model.

Second, to select the contextual variables, we applied a univariate linear regression model with the aggregate syphilis prevalence rate in each district as the dependent variable and contextual variables as independent variables. Contextual variables with $\mathrm{p}$ values $<0.10$ in the univariate linear regression model were added to the previous multilevel logistic regression model. We also included the aggregate baseline of each district's syphilis rate as an additional district-specific variable. After removing the contextual variables with $p>0.05$, we obtained another model with individual and contextual variables. The aggregate baseline of syphilis prevalence was the only district-level variable found to be significantly associated with the dependent variable.

To the last model described above, we added the three pairs of district-level programme variables (2006 value and difference between 2008 and 2006), along with interaction terms between rounds and the difference in programme indicators between 2008 and 2006. The programme indicators reflecting a significant interaction $(p<0.05)$ with the round were retained, as they show the correlation between the change in programme indicators and that of syphilis prevalence. Finally, as we were interested in factors affecting the different outcomes between the IBBA rounds, we examined the interaction of rounds with each of the other individual and district-level contextual factors included in the last multilevel model described above. We included all the interactions with a $\mathrm{p}$ value $<0.05$ in this final model. All these analyses used Stata/IC release 12.1 for Windows (StataCorp LP, College Station, Texas, USA).

\section{RESULTS}

The proportion of men approached who provided a blood sample was relatively low, but increased from round 1 (46.2\%) to round $2(57.5 \%)$. The response rate was higher in Karnataka state in both rounds $(80.5 \%$ in round 1 and $91.5 \%$ in round 2$)$. District-specific response rates for both rounds are provided in online supplementary appendix table 2 .

Overall, 7071 and 6859 clients provided serum samples in round 1 and round 2, respectively. Syphilis prevalence declined from $4.8 \%$ (95\% CI $4.3 \%$ to $5.3 \%$ ) in round 1 to $2.6 \%(95 \%$ CI $2.3 \%$ to $3.0 \%$ ) in round 2. In Andhra Pradesh and Karnatka, we observed a considerable decline between the two rounds (table 1). The decline in syphilis prevalence was significant in nine of 17 districts between the two rounds, but a large increase was seen in one district (Chennai). High-titre syphilis (rapid plasma reagin titre $\geq 8)$ declined $(\mathrm{p}=0.017)$ from $1.6 \%(95 \% \mathrm{CI}$ $1.3 \%$ to $1.9 \%$ ) in round 1 to $1.2 \%$ (95\% CI $0.9 \%$ to $1.4 \%)$ (data not shown).

Overall, HIV prevalence declined from 5.4\% (95\% CI 4.8\% to $5.9 \%)$ in round 1 to $4.9 \%$ (95\% CI $4.4 \%$ to $5.4 \%)$ in round 2 . Surprisingly, HIV prevalence in Chennai district increased between the study rounds. Though HIV prevalence declined in 12 districts, the decline was significant in only two districts. When we excluded the data from Chennai, we noticed a statistically significant decline in HIV prevalence between study rounds, from $5.5 \%$ (95\% CI $5.0 \%$ to $6.1 \%)$ to $4.5 \%(95 \% \mathrm{CI}$ $4.0 \%$ to $5.0 \%)$. Overall, in the non-Karnataka districts, CT prevalence declined from $1.7 \%$ in round 1 to $0.7 \%$ in round 2 . However, NG prevalence was lower at $0.4 \%$ in round 1 and $0.2 \%$ in round 2 .

Differences in FSW' clients' demographic and behavioural characteristics between study rounds were examined (see online supplementary appendix table 3 ). Consistent condom use with FSWs increased noticeably from round $1(37 \%)$ to round 2 (61\%), and other significant differences in demographic and behavioural characteristics were seen between rounds.

Syphilis prevalence increased with client age (table 2). Similarly, syphilis rates were higher among illiterate clients, 
Table 1 Comparison of the prevalence of syphilis*, HIV, CT and NG between round 1 and round 2 IBBAs among clients of FSWs by district and state

\begin{tabular}{|c|c|c|c|c|c|c|c|c|c|c|c|c|}
\hline \multirow[b]{2}{*}{ State/district } & \multicolumn{3}{|c|}{ Syphilis prevalence } & \multicolumn{3}{|l|}{ HIV prevalence } & \multicolumn{3}{|l|}{ CT prevalence } & \multicolumn{3}{|l|}{ NG prevalence } \\
\hline & $\begin{array}{l}\text { Round } 1 \\
\%(95 \% \mathrm{Cl})\end{array}$ & $\begin{array}{l}\text { Round } 2 \\
\%(95 \% \mathrm{Cl})\end{array}$ & $\mathrm{p}$ Value & $\begin{array}{l}\text { Round } 1 \\
\%(95 \% \mathrm{Cl})\end{array}$ & $\begin{array}{l}\text { Round } 2 \\
\%(95 \% \mathrm{Cl})\end{array}$ & $\mathrm{p}$ Value & $\begin{array}{l}\text { Round } 1 \\
\%(95 \% \mathrm{Cl})\end{array}$ & $\begin{array}{l}\text { Round } 2 \\
\%(95 \% \mathrm{Cl})\end{array}$ & $\mathrm{p}$ Value & $\begin{array}{l}\text { Round } 1 \\
\%(95 \% \mathrm{Cl})\end{array}$ & $\begin{array}{l}\text { Round } 2 \\
\%(95 \% \mathrm{Cl})\end{array}$ & $p$ Value \\
\hline Andhra Pradesh & 6.1 (5.1 to 7.1 ) & 1.3 (0.8 to 1.8 ) & $<0.001$ & 6.5 (5.5 to 7.6$)$ & 5.2 (4.2 to 6.2$)$ & 0.074 & $1.2(0.6$ to 1.8$)$ & $0.6(0.3$ to 0.9$)$ & 0.062 & $0.4(0.1$ to 0.8$)$ & 0.0 (NE) & $\mathrm{NE}$ \\
\hline East Godavari & 7.1 (4.6 to 9.6 ) & 2.2 (0.8 to 3.7 ) & 0.001 & 9.1 (6.3 to 11.8 ) & 7.2 (4.7 to 9.8 ) & 0.345 & $1.2(0.0$ to 2.3$)$ & $1.0(0.0$ to 2.0$)$ & 0.817 & $0.0(0.0$ to 0.0$)$ & 0.0 (NE) & NE \\
\hline Guntur & 11.2 (8.1 to 14.3$)$ & $1.0(0.0$ to 2.0$)$ & $<0.001$ & 7.5 (4.9 to 10.1$)$ & 5.9 (3.6 to 8.2 ) & 0.372 & $0.9(0.0$ to 2.1$)$ & 0.3 (0.0 to 0.7$)$ & 0.278 & $0.0(0.0$ to 0.0$)$ & 0.0 (NE) & NE \\
\hline Hyderabad & 5.4 (3.2 to 7.6$)$ & 2.3 (0.8 to 3.7$)$ & 0.019 & 3.7 (1.9 to 5.5$)$ & 5.3 (3.1 to 7.4$)$ & 0.285 & $2.0(0.4$ to 3.5$)$ & $1.5(0.3$ to 2.7$)$ & 0.647 & $0.0(0.0$ to 0.0$)$ & 0.0 (NE) & NE \\
\hline Vishakhapatnam & $3.2(1.5$ to 5.0$)$ & $1.0(0.0$ to 2.0$)$ & 0.026 & 8.0 (5.3 to 10.6$)$ & 3.5 (1.7 to 5.2 ) & 0.006 & 0.5 (0.0 to 1.3$)$ & 0.3 (0.0 to 0.7 ) & 0.666 & 1.8 (0.1 to 3.6$)$ & 0.0 (NE) & $\mathrm{NE}$ \\
\hline Warangal & $3.5(1.7$ to 5.3$)$ & $0.3(0.0$ to 0.7$)$ & 0.001 & 4.5 (2.5 to 6.5$)$ & $4.2(2.3$ to 6.2$)$ & 0.857 & $1.2(0.0$ to 2.4$)$ & 0.0 (NE) & $\mathrm{NE}$ & 0.6 (0.0 to 1.4$)$ & 0.0 (NE) & $\mathrm{NE}$ \\
\hline Maharashtra & 5.0 (3.9 to 6.1$)$ & 3.9 (2.9 to 4.8$)$ & 0.126 & 7.6 (6.3 to 8.9$)$ & 6.1 (4.9 to 7.2 ) & 0.078 & 2.7 (1.9 to 3.5$)$ & 1.1 (0.6 to 1.6$)$ & 0.001 & $0.7(0.3$ to 1.1$)$ & $0.6(0.2$ to 1.0$)$ & 0.682 \\
\hline Mumbai & 3.3 (1.5 to 5.1$)$ & $4.9(2.7$ to 7.0$)$ & 0.277 & 8.6 (5.9 to 11.4 ) & 5.7 (3.3 to 8.0$)$ & 0.112 & 4.3 (2.3 to 6.3$)$ & 2.4 (0.9 to 4.0$)$ & 0.150 & 1.0 (0.0 to 2.0$)$ & $1.6(0.3$ to 2.9$)$ & 0.466 \\
\hline Parbhani & $3.2(1.5$ to 4.9$)$ & $3.0(1.4$ to 4.7$)$ & 0.884 & $5.0(2.8$ to 7.1$)$ & 3.3 (1.5 to 5.1$)$ & 0.239 & 2.7 (1.1 to 4.3$)$ & 0.0 (NE) & NE & $0.5(0.0$ to 1.2$)$ & 0.0 (NE) & NE \\
\hline Pune & 6.0 (3.7 to 8.3 ) & 3.2 (1.5 to 4.9$)$ & 0.061 & 6.5 (4.1 to 8.9$)$ & 6.9 (4.5 to 9.4$)$ & 0.800 & $2.5(1.0$ to 4.0$)$ & $1.0(0.0$ to 2.0$)$ & 0.103 & $0.3(0.0$ to 0.7$)$ & $0.5(0.0$ to 1.2$)$ & 0.567 \\
\hline Yevatmal & 7.5 (4.9 to 10.1$)$ & 4.5 (2.5 to 6.5$)$ & 0.073 & 10.5 (7.5 to 13.5$)$ & 8.3 (5.6 to 11.0$)$ & 0.270 & $1.3(0.2$ to 2.3$)$ & $1.0(0.0$ to 2.0$)$ & 0.735 & $1.0(0.0$ to 2.0$)$ & 0.3 (0.0 to 0.7$)$ & 0.177 \\
\hline Tamil Nadu & 3.8 (2.7 to 4.9$)$ & 4.6 (3.4 to 5.8 ) & 0.341 & 2.7 (1.8 to 3.6) & 5.9 (4.6 to 7.2 ) & $<0.001$ & 0.8 (0.3 to 1.3$)$ & 0.4 (0.1 to 0.8$)$ & 0.188 & 0.0 (NE) & 0.0 (NE) & $\mathrm{NE}$ \\
\hline Chennai & 4.4 (2.4 to 6.4$)$ & 11.8 (8.6 to 14.9$)$ & $<0.001$ & 2.2 (0.8 to 3.7 ) & 12.0 (8.9 to 15.2$)$ & $<0.001$ & 1.5 (0.3 to 2.7$)$ & 0.0 (NE) & $\mathrm{NE}$ & 0.0 (NE) & 0.0 (NE) & NE \\
\hline Madurai & $3.0(1.3$ to 4.7$)$ & $1.0(0.0$ to 2.0$)$ & 0.043 & 2.2 (0.8 to 3.7$)$ & 3.7 (1.9 to 5.6$)$ & 0.216 & $0.0(\mathrm{NE})$ & $0.8(0.0$ to 1.6$)$ & $\mathrm{NE}$ & 0.0 (NE) & 0.0 (NE) & NE \\
\hline Salem & 4.0 (2.1 to 6.0$)$ & $1.0(0.0$ to 1.9$)$ & 0.005 & 3.5 (1.7 to 5.4$)$ & 2.0 (0.6 to 3.3$)$ & 0.173 & $1.0(0.0$ to 2.0$)$ & 0.5 (0.0 to 1.2$)$ & 0.393 & $0.0(\mathrm{NE})$ & 0.0 (NE) & NE \\
\hline Karnataka & 3.9 (3.1 to 4.7$)$ & 1.8 (1.2 to 2.3$)$ & $<0.001$ & 4.2 (3.4 to 5.0$)$ & 3.3 (2.6 to 4.1$)$ & 0.124 & 2.3 (1.7 to 2.8$)$ & NA & NA & $0.6(0.3$ to 0.9$)$ & NA & NA \\
\hline Bangalore Urban & 4.5 (2.8 to 6.1$)$ & 0.8 (0.1 to 1.6$)$ & $<0.001$ & 2.4 (1.2 to 3.5$)$ & 1.9 (0.9 to 3.0$)$ & 0.587 & 3.1 (1.8 to 4.4$)$ & NA & NA & $0.6(0.0$ to 1.2$)$ & NA & NA \\
\hline Belgaum & 3.9 (2.0 to 5.8$)$ & $2.0(0.5$ to 3.4$)$ & 0.122 & 6.6 (4.2 to 9.0$)$ & 3.0 (1.3 to 4.6$)$ & 0.014 & $1.2(0.2$ to 2.3$)$ & NA & NA & 0.0 (0.0 to 0.0$)$ & NA & NA \\
\hline Bellary & 6.0 (3.7 to 8.3 ) & 2.7 (1.0 to 4.4$)$ & 0.030 & 5.4 (3.3 to 7.6$)$ & 6.8 (4.3 to 9.3 ) & 0.415 & 1.7 (0.4 to 2.9$)$ & NA & NA & 0.5 (0.0 to 1.1$)$ & NA & NA \\
\hline Shimoga & 2.1 (0.8 to 3.5$)$ & 1.5 (0.2 to 2.8$)$ & 0.527 & 2.4 (0.9 to 3.8$)$ & $1.9(0.5$ to 3.2$)$ & 0.630 & $0.7(0.0$ to 1.5$)$ & NA & NA & 0.5 (0.0 to 1.1$)$ & NA & NA \\
\hline Mysore & 2.9 (1.3 to 4.6$)$ & 2.4 (0.9 to 3.8$)$ & 0.609 & 5.4 (3.3 to 7.6$)$ & 4.0 (2.1 to 5.9$)$ & 0.331 & 4.0 (2.1 to 5.9$)$ & NA & NA & $1.4(0.3$ to 2.5$)$ & NA & NA \\
\hline Total & 4.8 (4.3 to 5.3$)$ & 2.6 (2.3 to 3.0$)$ & $<0.001$ & 5.4 (4.8 to 5.9$)$ & 4.9 (4.4 to 5.4$)$ & 0.227 & 1.9 (1.5 to 2.2$)$ & $0.7(0.5$ to 1.0$)$ & $<0.001+$ & $0.5(0.3$ to 0.6$)$ & $0.2(0.1$ to 0.3$)$ & $0.058+$ \\
\hline
\end{tabular}

V Value based on Peason $\chi^{2}$ test.

*A subject was considered as having active syphilis when both the rapid plasma reagin and Treponema pallidum haemaglutination assay tests were positive.

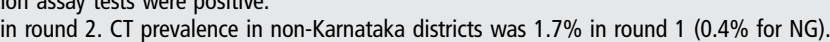

CT, Chlamydia trachomatis; FSW, female sex worker; IBBA, integrated behavioural and biological assessment survey; NA, not available; NE, not estimated; NG, Neisseria gonorrhoeae. 
Table 2 Syphilis prevalence among clients of FSWs, from IBBA round 1 and round 2 data, by individual characteristics

\begin{tabular}{|c|c|c|c|}
\hline Characteristics & $\begin{array}{l}\text { Round } 1 \\
\%(95 \% \mathrm{Cl})\end{array}$ & $\begin{array}{l}\text { Round } 2 \\
\%(95 \% \mathrm{Cl})\end{array}$ & $\begin{array}{l}\text { Total } \\
\%(95 \% \mathrm{Cl})\end{array}$ \\
\hline \multicolumn{4}{|c|}{ Age of respondent } \\
\hline$<25$ & 2.6 (1.9 to 3.3$)$ & $1.4(0.9$ to 1.9$)$ & 2.1 (1.6 to 2.5 ) \\
\hline $25-34$ & 4.6 (3.8 to 5.4 ) & 2.4 (1.9 to 3.0$)$ & 3.5 (3.0 to 3.9 ) \\
\hline$\geq 35$ & 7.3 (6.2 to 8.4$)$ & 4.1 (3.2 to 4.9$)$ & 5.7 (5.0 to 6.4$)$ \\
\hline \multicolumn{4}{|c|}{ Can read and write } \\
\hline No & 7.3 (6.1 to 8.5$)$ & $3.2(2.3$ to 4.0$)$ & 5.3 (4.6 to 6.1$)$ \\
\hline Yes & 3.9 (3.4 to 4.4$)$ & 2.5 (2.0 to 2.9 ) & 3.2 (2.8 to 3.5 ) \\
\hline \multicolumn{4}{|l|}{ Marital status } \\
\hline $\begin{array}{l}\text { Currently } \\
\text { married }\end{array}$ & 5.9 (5.2 to 6.6 ) & 2.9 (2.4 to 3.4$)$ & 4.4 (3.9 to 4.8 ) \\
\hline $\begin{array}{l}\text { Separated/ } \\
\text { divorced/ } \\
\text { widowed }\end{array}$ & 8.8 (4.8 to 12.8 ) & 4.7 (2.0 to 7.5 ) & 6.6 (4.2 to 9.0$)$ \\
\hline $\begin{array}{l}\text { Never } \\
\text { married }\end{array}$ & 2.7 (2.1 to 3.3 ) & 2.0 (1.4 to 2.6 ) & 2.4 (2.0 to 2.8 ) \\
\hline \multicolumn{4}{|l|}{ Age at first sex } \\
\hline$<20$ & 4.8 (4.1 to 5.5$)$ & 2.7 (2.2 to 3.2 ) & 3.8 (3.4 to 4.2 ) \\
\hline $20-24$ & 4.7 (3.9 to 5.5$)$ & 2.3 (1.8 to 2.9 ) & 3.5 (3.0 to 4.0$)$ \\
\hline$\geq 25$ & 5.0 (3.2 to 6.7$)$ & 3.7 (2.0 to 5.3 ) & 4.4 (3.1 to 5.6$)$ \\
\hline \multicolumn{4}{|c|}{ Age at first paid sex } \\
\hline$<20$ & 4.5 (3.7 to 5.3 ) & 2.5 (1.9 to 3.2$)$ & 3.6 (3.1 to 4.1 ) \\
\hline $20-24$ & 5.0 (4.3 to 5.7 ) & 2.6 (2.0 to 3.1 ) & 3.8 (3.4 to 4.3 ) \\
\hline$\geq 25$ & 4.9 (3.6 to 6.2 ) & 2.9 (2.1 to 3.7$)$ & 3.7 (3.0 to 4.4$)$ \\
\hline \multicolumn{4}{|l|}{ Typology of FSWs } \\
\hline Public place & 4.2 (3.5 to 5.0 ) & 2.9 (2.3 to 3.5$)$ & 3.6 (3.1 to 4.0$)$ \\
\hline Brothel & 5.4 (4.6 to 6.3$)$ & 3.6 (2.8 to 4.4$)$ & $4.6(4.0$ to 5.2$)$ \\
\hline Home & 4.5 (3.3 to 5.7 ) & 0.8 (0.2 to 1.4$)$ & 2.9 (2.2 to 3.7$)$ \\
\hline Other & 4.9 (2.5 to 7.4$)$ & $1.3(0.5$ to 2.1$)$ & $2.3(1.4$ to 3.1$)$ \\
\hline \multicolumn{4}{|c|}{ Consistent condom use with FSW } \\
\hline No & $5.4(4.7$ to 6.1$)$ & 3.9 (3.2 to 4.7$)$ & $4.8(4.3$ to 5.3$)$ \\
\hline Yes & $3.6(2.9$ to 4.4$)$ & 1.8 (1.4 to 2.2$)$ & 2.5 (2.1 to 2.9$)$ \\
\hline \multicolumn{4}{|c|}{ Anal sex with a man/transgender in past 6 months } \\
\hline No & 4.7 (4.2 to 5.2$)$ & 2.4 (2.0 to 2.8$)$ & 3.6 (3.3 to 3.9 ) \\
\hline Yes & $6.3(4.1$ to 8.5$)$ & 4.1 (2.8 to 5.4 ) & 4.9 (3.7 to 6.0$)$ \\
\hline \multicolumn{4}{|l|}{ Circumcised } \\
\hline No & 4.8 (4.3 to 5.4$)$ & 2.7 (2.3 to 3.1$)$ & $3.8(3.5$ to 4.1$)$ \\
\hline Yes & 4.5 (3.2 to 5.7$)$ & 2.1 (1.3 to 3.0$)$ & 3.3 (2.6 to 4.1$)$ \\
\hline \multicolumn{4}{|c|}{ HIV infection status } \\
\hline Negative & 4.1 (3.6 to 4.5$)$ & $1.6(1.3$ to 1.9$)$ & $2.8(2.6$ to 3.1$)$ \\
\hline Positive & 17.1 (13.4 to 20.9$)$ & 22.2 (17.8 to 26.6$)$ & 19.5 (16.7 to 22.4$)$ \\
\hline
\end{tabular}

those who had sex with brothel-based FSWs, those reporting anal sex with a man or male transgender in the past 6 months and those with HIV. As expected, syphilis prevalence was lower among clients who reported consistently using condoms with FSWs.

Table 3 shows the results of the multilevel logistic regression models. The left columns provide results from the multilevel model, including only the significant individual characteristics and baseline syphilis prevalence without interaction and programme indicators. The model shows that syphilis prevalence among FSWs' clients declined between the two survey rounds (adjusted OR $=0.49$, 95\% CI 0.38 to 0.62 ). Syphilis prevalence increased with age and was lower among literate clients. Clients who had sex with brothel-based FSWs had higher syphilis prevalence than those who had sex with home-based FSWs.
Clients who had sex with a man or male transgender in the past 6 months had higher syphilis prevalence. Consistent condom use with FSWs was associated with lower syphilis prevalence. Similarly, HIV infection increased the likelihood of syphilis. Furthermore, baseline syphilis prevalence was largely associated with overall syphilis prevalence.

We introduced the interaction between rounds and individual variables, as well as programme indicators, into the model to examine their influence on the decline in syphilis prevalence between the study rounds (see the right-hand columns of table 3). We observed a negative interaction between the rounds and a difference in programme coverage of FSWs between 2008 and 2006. Other significant interactions between the rounds were seen for baseline syphilis prevalence, HIV infection status and typology of the FSWs. The variance of the random intercept was reduced from 0.17 in the null model to 0.07 in the model, with individual variables with random slope. The random intercept from the final multilevel model indicates that after the introduction of significant individual characteristics and programme indicators, the unexplained variation at district level was drastically reduced $(0.17$ to insignificant). The random coefficient for the round indicates significant heterogeneity in the changes in syphilis prevalence across districts, but its variance was reduced after introducing the programme variables and interaction terms. We found a significant interaction between rounds and HIV infection, with a significant decline in syphilis prevalence between the two survey rounds among FSWs' clients without $\mathrm{HIV}(\mathrm{OR}=0.35, \mathrm{p}<0.001)$ (table 4), whereas there was a non-significant increase in syphilis among clients with HIV infection $(\mathrm{OR}=1.24, \mathrm{p}=0.322)$. The decline in syphilis among clients was significant across all categories of FSW typologies, but was greater among home-based FSWs' clients. The decline in syphilis prevalence was small and not significant when the coverage of FSWs by the programme was higher in 2006 than in 2008. However, it became greater as the coverage of FSWs by the programme between 2006 and 2008 increased and statistically significant starting from the first quartile.

\section{DISCUSSION}

We assessed the effect over time of changes in FSW programme coverage on the lower syphilis rate among FSWs' clients in the second IBBA round. The programme indicators among FSWs were used to assess the impact on clients, since a direct and strong correlation between HIV prevalence among FSWs and their clients was identified in another Indian study. ${ }^{22}$ In addition, studies elsewhere have shown declines in client STI prevalence as a result of interventions with FSWs. ${ }^{23} 24$ The Avahan programme is only directly involved with FSWs' clients in condom social marketing and franchised STI clinics. Thus, we were interested in assessing the indirect effect of programme indicators that were very specific to FSWs on syphilis prevalence among their clients.

We used multilevel analysis controlling for potential individual and contextual confounding factors, as well as for baseline syphilis prevalence at the district level and its interaction with the survey round, which explains why a decrease in prevalence is more likely in districts with higher baseline values. Syphilis prevalence declined significantly among FSWs' clients (about 90\%) in correlation with increases in Avahan programme coverage among FSWs. Greater increases in district-level programme coverage among FSWs led to larger decreases in syphilis prevalence, with no significant decrease in districts without improvement in coverage. Perhaps integrated HIV preventive interventions aimed at reaching both FSWs and their clients can significantly affect sexual behaviour and reduce STI prevalence. ${ }^{25}$ Evidence suggests that consistent condom use during commercial sex has increased as a result of 
Table 3 Multilevel logistic regression model of determinants of syphilis prevalence among clients of FSWs, IBBA round 1 and round 2

\begin{tabular}{|c|c|c|c|c|c|c|}
\hline \multirow{2}{*}{$\begin{array}{l}\text { Characteristics } \\
\text { Fixed part of the model }\end{array}$} & & \multicolumn{2}{|c|}{$\begin{array}{l}\text { Without programme variable and } \\
\text { interaction terms }\end{array}$} & \multicolumn{3}{|c|}{$\begin{array}{l}\text { With programme variable and } \\
\text { interaction terms }\end{array}$} \\
\hline & AOR & $\mathrm{p}$ Value & $95 \% \mathrm{Cl}$ & AOR & $\mathrm{p}$ Value & $95 \% \mathrm{Cl}$ \\
\hline Constant & 0.01 & $<0.001$ & 0.01 to 0.02 & 0.01 & 0.030 & 0.01 to 0.03 \\
\hline \multicolumn{7}{|l|}{ IBBA round } \\
\hline \multicolumn{7}{|l|}{ Round 1} \\
\hline Round 2 & 0.49 & $<0.001$ & 0.38 to 0.62 & 0.33 & 0.066 & 0.10 to 1.08 \\
\hline \multicolumn{7}{|l|}{ Age of respondent (years) } \\
\hline \multicolumn{7}{|l|}{$<25$} \\
\hline $25-34$ & 1.43 & 0.009 & 1.09 to 1.88 & 1.47 & 0.006 & 1.12 to 1.92 \\
\hline$\geq 35$ & 2.32 & $<0.001$ & 1.76 to 3.04 & 2.31 & $<0.001$ & 1.76 to 3.03 \\
\hline \multicolumn{7}{|l|}{ Can read and write } \\
\hline \multicolumn{7}{|l|}{ No } \\
\hline Yes & 0.66 & $<0.001$ & 0.54 to 0.81 & 0.65 & $<0.001$ & 0.53 to 0.80 \\
\hline \multicolumn{7}{|l|}{ Typology of FSWs } \\
\hline \multicolumn{2}{|l|}{ Public place-based } & 0.436 & 0.83 to 1.56 & 0.94 & 0.734 & 0.67 to 1.33 \\
\hline \multirow{2}{*}{\multicolumn{2}{|c|}{$\begin{array}{l}\text { Brothel-based } \\
\text { Home-based }\end{array}$}} & 0.092 & 0.95 to 1.88 & 1.11 & 0.575 & 0.78 to 1.58 \\
\hline & & \multicolumn{5}{|c|}{ Home-based } \\
\hline Other & 1.09 & 0.733 & 0.67 to 1.77 & 1.27 & 0.449 & 0.69 to 2.33 \\
\hline \multicolumn{7}{|c|}{ Anal sex with a man/transgender in past 6 months } \\
\hline \multicolumn{7}{|c|}{ No } \\
\hline Yes & 1.58 & 0.002 & 1.18 to 2.11 & 1.53 & 0.005 & 1.14 to 2.06 \\
\hline \multicolumn{7}{|l|}{ Consistent condom use with FSWs } \\
\hline \multicolumn{7}{|l|}{ No } \\
\hline Yes & 0.80 & 0.034 & 0.64 to 0.98 & 0.85 & 0.141 & 0.69 to 1.05 \\
\hline \multicolumn{7}{|l|}{ HIV infection status } \\
\hline \multicolumn{7}{|l|}{ Negative } \\
\hline \multicolumn{2}{|l|}{ Positive } & $<0.001$ & 5.51 to 8.59 & 4.14 & $<0.001$ & 3.04 to 5.64 \\
\hline \multicolumn{2}{|l|}{ Baseline syphilis prevalence } & $<0.001$ & 1.10 to 1.30 & 1.18 & $<0.001$ & 1.10 to 1.26 \\
\hline \multicolumn{7}{|l|}{ Programme indicators } \\
\hline \multicolumn{2}{|l|}{ FSW programme coverage at baseline } & & & 1.00 & 0.685 & 0.99 to 1.01 \\
\hline \multicolumn{2}{|c|}{ Difference in coverage between the two rounds } & & & 1.00 & 0.327 & 1.00 to 1.01 \\
\hline Interaction between round and & & & & & & \\
\hline Difference in coverage between the & ounds & & & 0.98 & 0.023 & 0.97 to 0.99 \\
\hline Baseline HIV prevalence & & & & 0.85 & 0.003 & 0.76 to 0.94 \\
\hline Status of HIV & & & & 3.57 & $<0.001$ & 2.26 to 5.64 \\
\hline Typology of FSWs & & & & & & \\
\hline Public place-based & & & & 4.61 & 0.003 & 1.67 to 12.72 \\
\hline Brothel-based & & & & 4.04 & 0.006 & 1.48 to 11.04 \\
\hline Other & & & & 2.33 & 0.186 & 0.67 to 8.12 \\
\hline Random part of the model & & & & & & \\
\hline Estimated district-level variance of & Estimated variance & $95 \% \mathrm{Cl}$ of vari & & Estimated variance & $95 \% \mathrm{Cl}$ & \\
\hline Round & 0.07 & 0.03 to 0.17 & & 0.04 & 0.01 to & \\
\hline Intercept & 0.00 & Not significantl] & it from 0 & 0.00 & Not sigr & different from 0 \\
\hline
\end{tabular}

AOR, adjusted OR; FSW, female sex worker; IBBA, integrated behavioural and biological assessment survey.

the Avahan programme and this has contributed to reduced HIV/ STI transmission between FSWs and clients in Karnataka. ${ }^{13} 14$ A mathematical modelling study indicated that during the first 4 years of Avahan, most of the HIV infections averted owing to the programme were among FSWs clients, followed by the general population, men who have sex with men and FSWs. ${ }^{14}$ Importantly, analysis of data from Karnataka found a doseresponse relationship between intervention exposure and self-reported condom use in commercial partnerships. ${ }^{26}$ Much of the increase in consistent condom use can be attributed to Avahan, especially in districts where it has remained the only prevention programme in place for high-risk groups. ${ }^{13}$ In Thailand, explicit messages to men about the risks of STIs from unprotected commercial sex resulted in higher reported condom use, lower reported numbers of sex worker visits and lower infection rates. ${ }^{27}$ Social marketing of condoms has effectively increased supply and demand. ${ }^{28}$ The success of the intervention efforts depends not on reaching all people but on reaching the right people (those most at risk) with effective interventions. Prevention efforts that effectively reduce transmission in the high partner 'core' population are necessary and often sufficient, to reduce transmission in the population at large..$^{29}$

A study using data from the two IBBA rounds among FSWs in 24 Avahan programme districts showed HIV prevalence declining from 2006 to 2007 (17.0\%) to 2010 (14.2\%). ${ }^{30}$ Furthermore, the syphilis prevalence among FSWs declined 
Table 4 Changes in syphilis prevalence among clients of FSWs between the study rounds at different levels of the independent variables having a significant statistical interaction with the study round

\begin{tabular}{|c|c|c|c|c|}
\hline Factors having a significant interaction with the round & AOR & $95 \% \mathrm{Cl}$ & p Value & $p$ Value of the interaction term \\
\hline Baseline syphilis prevalence & & & & 0.003 \\
\hline Minimum value $(2.13 \%)$ & 0.78 & 0.53 to 1.16 & 0.220 & \\
\hline 25th Centile $(3.23 \%)$ & 0.65 & 0.48 to 0.89 & 0.007 & \\
\hline 50th Centile (4.04\%) & 0.57 & 0.44 to 0.75 & $<0.001$ & \\
\hline 75th Centile (5.97\%) & 0.42 & 0.32 to 0.55 & $<0.001$ & \\
\hline Maximum (11.22\%) & 0.18 & 0.09 to 0.37 & $<0.001$ & \\
\hline Difference in covered value & & & & 0.023 \\
\hline Minimum $(-5.9 \%)$ & 0.92 & 0.59 to 1.43 & 0.711 & \\
\hline 25th Centile (17.9\%) & 0.61 & 0.47 to 0.80 & $<0.001$ & \\
\hline 50th Centile $(26.4 \%)$ & 0.53 & 0.41 to 0.67 & $<0.001$ & \\
\hline 75th Centile $(42.6 \%)$ & 0.40 & 0.30 to 0.53 & $<0.001$ & \\
\hline Maximum* (106.3\%) & 0.13 & 0.06 to 0.31 & $<0.001$ & \\
\hline HIV infection status & & & & $<0.001$ \\
\hline Negative & 0.35 & 0.27 to 0.47 & $<0.001$ & \\
\hline Positive & 1.24 & 0.81 to 1.89 & 0.322 & \\
\hline \multicolumn{5}{|l|}{ Typology of FSWs } \\
\hline Public place-based & 0.54 & 0.38 to 0.76 & $<0.001$ & 0.003 \\
\hline Brothel-based & 0.65 & 0.45 to 0.93 & 0.018 & 0.006 \\
\hline Home-based & 0.12 & 0.05 to 0.30 & $<0.001$ & \\
\hline Other & 0.27 & 0.12 to 0.62 & 0.002 & 0.186 \\
\hline
\end{tabular}

significantly from $11.7 \%$ to $7.1 \%$. Similarly, the CT/NG prevalence among FSWs showed a significant decline $(7.2 \%$ to 5.9\%). These results suggest that Avahan intervention contributed to the lower rate of STI/HIV among FSWs and their clients.

Though, overall, syphilis prevalence among FSWs' clients decreased between the study rounds, surprisingly there was an increase in syphilis prevalence among FSW' clients in Chennai district. This probably underestimated the reduction in syphilis prevalence found among FSWs' clients between the study rounds. Data indicate that in Chennai the percentage of clients who had anal sex with a man or male transgender increased from round $1(3.2 \%)$ to round $2(30.0 \%)$. Similarly, in Chennai, the clients reporting condom use consistently with FSWs declined from $24.0 \%$ in round 1 to $12.0 \%$ in round 2 . These differences in FSWs' clients' characteristics might have led to an increase in syphilis prevalence in Chennai.

Along with programme coverage, baseline syphilis prevalence also influenced the decline in syphilis prevalence, with no significant decline in districts with low baseline prevalence. The greatest decline was in districts with the highest baseline syphilis prevalence (about 80\%). Similarly, FSWs' clients without HIV experienced a significant decline in syphilis prevalence of $65 \%$ between the two survey rounds. In addition, the decline in syphilis prevalence among FSWs' clients between the two rounds was found to be highest among clients of home-based FSWs (a decrease of about 90\%). HIV prevalence among home-based FSWs was lower than among FSWs of other typologies. ${ }^{31}$ Similarly, the decline in syphilis prevalence among clients of brothel-based FSWs was slightly lower.

This study has some limitations. It is based on client samples from FSW solicitation sites, such as public places, brothels, homes and other venues. Thus, all possible clients might not have been included in the sampling frame. Similarly, the sample consisted of clients who had paid for sex in the past month, which might have oversampled clients with frequent FSW contact, thus possibly over-representing higher-risk clients. In addition, since all behavioural responses were self-reported, the possibility of social desirability bias cannot be ruled out. Another limitation is that the response rate was generally low and increased greatly between rounds, with the potential of inducing biases in the trend analysis. Though we noticed significant changes in the characteristics of clients between study rounds, the absolute differences and their significance were mostly small, partly owing to large sample sizes.

In conclusion, in four south Indian states we observed a strong and favourable impact of the Avahan HIV prevention programme for FSWs in reducing their clients' rate of syphilis. This study also highlights the importance of scaling-up intervention programmes targeting FSWs, to reduce their rates of HIV/ STI infection and also those of their clients.

\section{Author affiliations}

${ }^{1}$ CHARME-India II Project, Bangalore, Karnataka, India

${ }^{2}$ Karnataka Health Promotion Trust, Bangalore, Karnataka, India

${ }^{3}$ Department of Epidemiology, National Institute of Mental Health and

Neurosciences, Bangalore, Karnataka, India

${ }^{4}$ St. John's Research Institute, Bangalore, Karnataka, India

${ }^{5}$ National AIDS Research Institute, Pune, India

${ }^{6} \mathrm{FHI} 360$, Washington, DC, USA

${ }^{7}$ URESP, Centre de recherche du CHU de Québec, Québec, Canada

${ }^{8}$ Département de mathématiques et statistique, Université Laval, Québec, Canada ${ }^{9}$ Department of Community Health Sciences, University of Manitoba, Winnipeg, Canada

${ }^{10}$ Département de médecine sociale et préventive, Université Laval, Québec, Canada

\section{Handling editor Jackie Cassell}

Contributors MA and TD initiated the study. SPR was responsible for the statistical analyses and the first draft of the manuscript. PB, MA, TD, TT and UKT contributed to the statistical analyses and interpretation of the data. MA, BMR, SI, RP, RA

MKM and SM were involved in the study design and integrated behavioural and biological assessment data collection. All participated in revising the manuscript and approved its final version.

Funding Support for this study was provided by the Bill \& Melinda Gates Foundation. The views expressed herein are those of the authors and do not 
necessarily reflect the official policy or position of the Bill \& Melinda Gates Foundation.

Competing interests None.

Patient consent Obtained.

Ethics approval St John's Medical College, Bangalore.

Provenance and peer review Not commissioned; externally peer reviewed.

Open Access This is an Open Access article distributed in accordance with the Creative Commons Attribution Non Commercial (CC BY-NC 3.0) license, which permits others to distribute, remix, adapt, build upon this work non-commercially, and license their derivative works on different terms, provided the original work is properly cited and the use is non-commercial. See: http://creativecommons.org/ licenses/by-nc/3.0/

\section{REFERENCES}

1 National AIDS Control Organization. HIV Sentinel Surveillance and HIV estimation in India, 2007: a technical brief. Ministry of Health and Family Welfare, 2007.

2 National Institute of Medical Statistics and National AIDS Control Organization. Technical report India HIV estimates. Ministry of Health and Family Welfare, 2010.

3 Over M, Piot P. HIV infection and sexually transmitted diseases. In: Jamison DT, Mosley WH, Measham AR, et al., eds. Disease control priorities in developing countries. New York: Oxford University Press, 1993:455-528.

4 Semple SJ, Strathdee SA, Gallardo CM, et al. Psychosexual and social-cognitive correlates of sexual risk behavior among male clients of female sex workers in Tijuana, Mexico. AIDS Care 2010;22:1473-80.

5 Lowndes $\mathrm{CM}$, Alary M, Meda $\mathrm{H}$, et al. Role of core and bridging groups in the transmission dynamics of HIV and sexually transmitted infections in Cotonou, Benin, West Africa. Sex Transm Infect 2002;78(Suppl 1):i69-77.

6 Arora PN, Sastry CV. HIV infection and genital ulcer disease. Indian J Sex Transm Dis 1992:13:71-3.

7 Lynn WA, Lightman S. Syphilis and HIV: a dangerous combination. Lancet Infect Dis 2004;4:456-66.

8 Buchacz K, Patel P, Taylor M, et al. Syphilis increases HIV viral load and decreases CD4 cell counts in HIV-infected patients with new syphilis infections. AIDS 2004;18:2075-9.

9 Mayaud P, McCormick D. Interventions against sexually transmitted infections (STI) to prevent HIV infection. Br Med Bull 2001:58:129-53.

10 Bill \& Melinda Gates Foundation. Avahan-The India AIDS Initiative: the business of HIV prevention at scale. New Delhi, India: Bill \& Melinda Gates Foundation, 2008

11 Chandrasekaran P, Dallabetta G, Loo V, et al. Evaluation design for large-scale HIV prevention programmes: the case of Avahan, the India AIDS initiative. AIDS 2008;22(Suppl 5):S1-15.

12 Boily MC, Lowndes CM, Vickerman P, et al. Evaluating large-scale HIV prevention interventions: study design for an integrated mathematical modelling approach. Sex Transm Infect 2007;83:582-9.

13 Boily MC, Pickles M, Lowndes CM, et al. Positive impact of a large-scale HIV prevention programme among female sex workers and clients in South India. AIDS 2013;27:1449-60.

14 Pickles M, Boily MC, Vickerman $\mathrm{P}$, et al. Assessment of the population-level effectiveness of the Avahan HIV-prevention programme in South India: a preplanned, causal-pathway-based modelling analysis. Lancet GH 2013:1:e289-99.
$15 \mathrm{Ng} \mathrm{M}$, Gakidou E, Levin-Rector A, et al. Assessment of population-level effect of Avahan, an HIV-prevention initiative in India. Lancet 2011;378:1643-52.

16 Banandur P, Mahajan U, Rajaram S, et al. Population-level impact of Avahan in Karnataka state, South India using multilevel statistical modelling techniques. J Acquir Immune Defic Syndr 2013;62:239-45.

17 Moses S, Ramesh BM, Nagelkerke NJD, et al. Impact of an intensive HIV prevention programme for female sex workers on HIV prevalence among antenatal clinic attenders in Karnataka state, south India: an ecological analysis. AIDS 2008;22 (Suppl 5):S101-8.

18 Subramanian T, Gupte MD, Paranjape RS, et al. HIV, sexually transmitted infections and sexual behaviour of male clients of female sex workers in Andhra Pradesh, Tamil Nadu and Maharasthra, India: results of a cross-sectional survey. AIDS 2008;22(Suppl 5):S69-79.

19 Shaw YS, Deering KN, Reza-Paul S, et al. Prevalence of HIV and sexually transmitted infections among clients of female sex workers in Karnataka, India: a cross-sectional study. BMC Public Health 2011;11(Suppl 6):S4.

20 Saidel T, Adhikary R, Mainkar M, et al. Baseline integrated behavioural and biological assessment among most at-risk populations in six high-prevalence states of India: design and implementation challenges. AIDS 2008;22(Suppl 5):S17-34.

21 Verma R, Shekhar A, Khobragade S, et al. Scale-up and coverage of Avahan: a large-scale HIV-prevention programme among female sex workers and men who have sex with men in four Indian states. Sex Transm Infect 2010;86(Suppl 1): i76-82.

22 Alary $M$, Jayachandran AA, Lowndes CM, et al. Ecological analysis of the association between high-risk population parameters and HIV prevalence among pregnant women enrolled in sentinel surveillance in four southern India states. Sex Transm Infect 2010;86:i10-16.

23 Steen R, Vuylsteke B, DeCoito T, et al. Evidence of declining STD prevalence in a South African mining community following a core-group intervention. Sex Transm Dis 2000:27:1-8.

24 Wi T, Ramos ER, Steen R, et al. STI declines among sex workers and clients following outreach, one time presumptive treatment and regular screening of sex workers in the Philippines. Sex Transm Infect 2006;82:386-91.

25 Lowndes CM, Alary M, Labbé A-C, et al. Interventions among male clients of female sex workers in Benin, West Africa: an essential component of targeted HIV preventive interventions. Sex Transm Infect 2007;83:577-81.

26 Deering $\mathrm{KN}$, Boily MC, Lowndes CM, et al. A dose-response relationship between exposure to a large-scale core group HIV prevention intervention and consistent condom use with different sexual partners of female sex workers in south India. BMC Public Health 2011;11(Suppl 6):S8.

27 Rojanapithayakorn W. The 100\% condom use programme in Asia. Reprod Health Matters 2006;14:41-52.

28 Eloundou-Enyegue PM, Meekers D, Calves AV. From awareness to adoption: the effect of AIDS education and condom social marketing on condom use in Tanzania (1993-96). J Biosoc Science 2005;37:257-68.

29 Steen R, Wi TE, Kamali A, et al. Control of sexually transmitted infections and prevention of HIV transmission: mending a fractured paradigm. Bull World Health Organ 2009;87:858-65

30 Alary M, Banandur P, Rajaram SP, et al. Increased HIV prevention program coverage and decline in HIV prevalence among female sex workers in south India. Sex Transm Infect 2013;89(Suppl 1):A58-9.

31 Ramesh BM, Moses S, Washington $\mathrm{R}$, et al. Determinants of HIV prevalence among female sex workers in four south Indian states: analysis of cross-sectional surveys in twenty-three districts. AIDS 2008;22(Suppl 5):S35-44. 